\title{
BMJ Open Epidemiology of undiagnosed depression in people with diabetes mellitus: a comparative analysis of Ireland, England and the USA
}

\author{
Niamh McGrath (D) , ${ }^{1}$ Kate O Neill (D) , ${ }^{1}$ Sheena M McHugh, ${ }^{1}$ Elaine Toomey, ${ }^{2}$ \\ Patricia M Kearney (ID ${ }^{1}$
}

To cite: McGrath N, 0 Neill K, McHugh SM, et al. Epidemiology of undiagnosed depression in people with diabetes mellitus: a comparative analysis of Ireland, England and the USA. BMJ Open 2021;11:e049155. doi:10.1136/ bmjopen-2021-049155

- Prepublication history and additional supplemental material for this paper are available online. To view these files, please visit the journal online (http://dx.doi.org/10.1136/ bmjopen-2021-049155).

Received 29 January 2021 Accepted 07 September 2021

Check for updates

(C) Author(s) (or their employer(s)) 2021. Re-use permitted under CC BY-NC. No commercial re-use. See rights and permissions. Published by BMJ.

${ }^{1}$ School of Public Health, University College Cork-National University of Ireland, Cork, Ireland

${ }^{2}$ School of Allied Health, University of Limerick, Limerick, Ireland

Correspondence to Ms Niamh McGrath; Niamh.mcgrath@ucc.ie

\section{ABSTRACT}

Objectives Improving detection of depression in people with diabetes is recommended. However, little is known about how different health systems compare in depression detection. We estimated and compared the (1) prevalence of depression detection in people with and without diabetes, and (2) association between diabetes and undiagnosed depression across three health systems. Design Cross-sectional analysis of three nationally representative studies: The Irish Longitudinal Study on Ageing, the English Longitudinal Study on Ageing and the Health and Retirement Study.

Setting Community-dwelling adults in Ireland, England and the USA.

Participants Adults aged $\geq 50$ years.

Primary and secondary outcome measures The primary outcome was depression diagnosis. The secondary outcome was any depression. Any depression was defined by the presence of self-reported doctordiagnosed depression or current depression symptoms on the Centre for Epidemiological Studies-Depression scale. Depression diagnosis was categorised as: undiagnosed, symptomatic and diagnosed, and asymptomatic and diagnosed. We estimated age-standardised prevalence of depression diagnosis by country and diabetes status. Anyone who self-reported having ever received a doctor diagnosis of diabetes was classified as having diabetes. Among respondents with depression, we estimated the association between diabetes and undiagnosed depression by country using multivariable logistic regression.

Results The prevalence of depression (diagnosed and undiagnosed) was higher in people with diabetes in each country with absolute rates varying by country; undiagnosed prevalence (Ireland: diabetes 10.1\% (95\% Cl $7.5 \%$ to $12.8 \%$ ) vs no diabetes $7.5 \%$ (95\% Cl $6.8 \%$ to $8.2 \%)$, England: diabetes $19.3 \%$ (95\% Cl $16.5 \%$ to $22.2 \%)$ vs no diabetes $11.8 \%(95 \% \mathrm{Cl} 11.0 \%$ to $12.6 \%)$, USA: diabetes $7.4 \%$ (95\% Cl 6.4\% to $8.4 \%$ ) vs no diabetes $6.1 \%(95 \% \mathrm{Cl} 5.7 \%$ to $6.6 \%))$. In the fully adjusted model, there was no clear pattern of association between diabetes status and undiagnosed depression; Ireland: $\mathrm{OR}=0.82$ (95\% Cl 0.5 to 1.3), England: $0 \mathrm{R}=1.47$ (95\% $\mathrm{Cl} 1.0$ to 2.1), USA: OR=0.80 (95\% Cl 0.7 to 1.0$)$.

Conclusions Although undiagnosed depression was more prevalent among people with diabetes, the relationship between diabetes and undiagnosed depression differed by

\section{STRENGTHS AND LIMITATIONS OF THIS STUDY}

$\Rightarrow$ The age-standardised prevalence of depression diagnosis, categorised as undiagnosed, symptomatic and diagnosed, and asymptomatic and diagnosed, was estimated by country and diabetes status (diabetes mellitus (DM) vs no DM) using data from three nationally representative studies.

$\Rightarrow$ Among respondents with depression, multivariable logistic regression models were used to estimate the association between diabetes and undiagnosed depression in each country.

$\Rightarrow$ Results are generalisable to adults aged 50 years and older in Ireland, England and the USA.

$\Rightarrow$ A comparable measure of depression was available across studies.

$\Rightarrow$ Depression management data (ie, medication use and/or attendance at psychological services) were not collected in all surveys, limiting the scope of the current analysis.

country. Targeted efforts are needed to improve depression detection among community-dwelling older adults, particularly those with diabetes.

\section{INTRODUCTION}

Diabetes is a serious global public health issue with type 2 diabetes accounting for approximately $90 \%$ of cases. ${ }^{1}$ Between 1980 and 2014 , the number of people with diabetes has almost quadrupled worldwide. ${ }^{2}$ Diabetes can lead to complications that adversely impact people with diabetes and burden health systems. ${ }^{3}$ Depression among people with diabetes is of growing concern. Depression is commonly reported as being three times higher in people with type 1 diabetes and nearly twice as prevalent in people with type 2 diabetes compared with those without. ${ }^{4}$ Among people with diabetes, depression is associated with increased risk of developing diabetes-related complications, ${ }^{5}$ increased mortality ${ }^{6}$ and increased costs to health 
systems. ${ }^{7}$ Prevalence estimates among people with type 2 diabetes vary across regions. ${ }^{8}$ However, less is known about the breakdown of depression by its detection status, that is, undiagnosed, diagnosed and symptomatic, and diagnosed and asymptomatic. ${ }^{910}$ Although variation in access to depression diagnosis and treatment in different countries has been reported in type 2 diabetes populations, ${ }^{9}$ there is a paucity of up-to-date nationally representative prevalence estimates of depression detection outside the USA. ${ }^{10}$ Cross-country comparisons of depression diagnosis are needed in diabetes populations because country-level factors may influence access to depression diagnosis and treatment. ${ }^{11}$ This may be due to health system differences influencing depression detection and management, ${ }^{11-13}$ such as health system financing ${ }^{12}$ and depression management. ${ }^{13}$ For instance, implementation of universal healthcare for depression in Chile resulted in increased self-reported depression diagnoses or physician consultations for depression. ${ }^{12}$ Regarding management, higher rates of antidepressant prescribing in the USA compared with the UK are associated with more conservative prescribing guidelines for depression in the UK. ${ }^{13}$

Diabetes has been associated with increased odds of depression diagnosis and treatment in the USA. ${ }^{14}$ However, the consistency of this association has not been compared across countries, despite health system differences in diabetes care which may influence the likelihood of depression and subsequent detection. For instance, poorer quality diabetes care may influence the likelihood of depression diagnosis in people with versus without diabetes via increased psychological burden of diabetes. A 2018 study demonstrated an association between quality of diabetes care and depression outcomes in people with diabetes in Europe using Euro Diabetes Index indicators for detection, care processes, access to care and outcomes. ${ }^{15}$ Specifically, in countries scoring in the highest quartile, having diabetes was associated with a $3 \%$ relative increase in depressive symptoms (95\% CI 1.00 to 1.05$)$ compared with a $22 \%(1.14-1.31)$ relative increase in countries scoring within the lowest quartile of diabetes care quality. ${ }^{16}$ The authors suggested related pathways for this association may include financial aspects of diabetes care, access to services and differential exposure to social determinants of health. These findings suggest that improved quality of diabetes care may reduce some of the psychological burden associated with living with diabetes. ${ }^{16}$ Countries vary in the extent to which psychosocial care is integrated into diabetes care. ${ }^{17}$ In 2012, approximately $70 \%$ of diabetes health professionals surveyed in the UK indicated major improvements were needed in the provision of psychological support and care compared with approximately $50 \%$ of US counterparts. ${ }^{17}$

This study uses data from three nationally representative surveys of adults aged 50 years and older in Ireland, England and the USA, that is, three high-income countries with different health system financing and organisation of diabetes care (see online supplemental file 1) to estimate and compare the (1) prevalence of depression detection in people with and without diabetes and (2) association between diabetes and undiagnosed depression.

\section{METHODS}

\section{Study design and data sources}

We conducted a cross-sectional analysis of three nationally representative ageing studies of community-dwelling adults aged $\geq 50$ years in Ireland (The Irish Longitudinal Study on Ageing; TILDA) ${ }^{18}$ England (the English Longitudinal Study on Ageing; ELSA) ${ }^{19}$ and the USA (the Health and Retirement Study; HRS) ${ }^{20}$ Established after HRS, TILDA and ELSA were designed to be comparable with HRS. All three studies collect detailed self-report sociodemographic, physical and mental health information. ${ }^{18-20}$ We used data from wave 1 TILDA, ${ }^{18}$ wave $5 \mathrm{ELSA}^{19}$ and wave 10 RAND $\mathrm{HRS}^{20}{ }^{20}$ which use corresponding data collection periods, that is, 2009-2011 (TILDA) and 2010 (ELSA and HRS). RAND HRS is a cleaned version of HRS which more closely corresponds with TILDA and ELSA. Table 1 details the design and population of each survey.

\section{Patient and public involvement}

This is a secondary analysis using data from the TILDA, ELSA and HRS studies. Adults aged 50 years and older, with or without diabetes, were not directly involved in the design or conduct of this study.

\section{Variables and definitions}

Diabetes mellitus

Anyone who self-reported having ever received a doctor diagnosis of diabetes was classified as having diabetes. All others were classified as having no diabetes.

\section{Depression}

Depression symptoms were assessed using the eight-item Centre for Epidemiological Studies-Depression (CES-D) self-report depression symptom measure. ${ }^{21}{ }^{22}$ Due to different response formats across surveys (ie, four-item response in TILDA and two-item response in ELSA and HRS), the maximum CES-D score in TILDA is 24 and 8 in ELSA and HRS. We applied the recommended CES-D cut-off score of $\geq 9$ for TILDA respondents ${ }^{22}$ and $\geq 4$ for ELSA and HRS respondent ${ }^{23}$ to indicate the presence of depression symptoms.

In each survey, participants were asked: 'Has a doctor ever told you that you have a psychological disorder?' TILDA and ELSA participants who answered yes then indicated from a list provided the problem they currently have or previously had. Those who indicated having ever received a diagnosis of 'depression' were categorised as having ever received a depression diagnosis. HRS participants who responded yes to the question 'Has a doctor ever told you that you have (chronic) depression?' were categorised as having ever received a depression diagnosis.

'No depression' was defined as scoring below the CES-D cut-off score and having never received a doctor diagnosis of depression. 'Any depression' was defined as 
Table 1 Design characteristics of TILDA, ELSA and HRS surveys

\begin{tabular}{|c|c|c|c|}
\hline & ${\text { TILDA (wave } 1)^{18}}^{18}$ & ELSA (wave 5) ${ }^{19}$ & HRS (wave 10$)^{20}$ \\
\hline $\begin{array}{l}\text { Sampling frame at } \\
\text { wave }\end{array}$ & $\begin{array}{l}\text { The sampling frame used } \\
\text { for wave } 1 \text { TILDA was } \\
\text { the Irish GeoDirectory; a } \\
\text { comprehensive and up-to- } \\
\text { date list of all residential } \\
\text { addresses in Ireland. }\end{array}$ & $\begin{array}{l}\text { The sampling frame used } \\
\text { for wave } 5 \text { ELSA comprised } \\
\text { participants of the Health } \\
\text { Survey for England from years } \\
1998,1999 \text { and } 2001 \text { and two } \\
\text { refreshment samples drawn } \\
\text { from the Health Survey for } \\
\text { England from years } 2001-2004 \\
\text { and } 2006 \text {. }\end{array}$ & $\begin{array}{l}\text { The sampling frame used for wave } 10 \text { HRS } \\
\text { comprised six cohorts born during differen } \\
\text { periods: the initial HRS cohort (born 1931- } \\
\text { 1941), the Asset and Health Dynamics } \\
\text { Among the Oldest Old (born 1890-1923), } \\
\text { the Children of the Depression (born 1924- } \\
\text { 1930), War Babies (born 1942-1947), Early } \\
\text { Baby Boomers (born 1948-1953) and Mid } \\
\text { Baby Boomers (born 1954-1959). }\end{array}$ \\
\hline Sampling design & $\begin{array}{l}\text { Multistage probability } \\
\text { sampling with each } \\
\text { residential address in the } \\
\text { country having an equal } \\
\text { probability of selection. }\end{array}$ & $\begin{array}{l}\text { Multistage stratified probability } \\
\text { sampling with postcode } \\
\text { sectors selected at the } \\
\text { first stage and household } \\
\text { addresses selected at the } \\
\text { second stage (Health Survey } \\
\text { for England). }\end{array}$ & $\begin{array}{l}\text { Multistage area probability design involving } \\
\text { geographical stratification and clustering } \\
\text { and oversampling of certain demographic } \\
\text { groups (all six cohorts). }\end{array}$ \\
\hline $\begin{array}{l}\text { Data collection } \\
\text { period at wave }\end{array}$ & 2009-2011 & 2010 & 2010 \\
\hline $\begin{array}{l}\text { Data collection } \\
\text { method }\end{array}$ & Face to face & Face to face & $\begin{array}{l}\text { Up until 2006, interviews were conducted } \\
\text { face to face. Since } 2006 \text {, half of the } \\
\text { samples are assigned a face-to-face } \\
\text { interview and the other half a telephone } \\
\text { interview. Respondents aged } 80 \text { years and } \\
\text { older complete face-to-face interviews. }\end{array}$ \\
\hline $\begin{array}{l}\text { Survey response rate } \\
\text { at wave }\end{array}$ & $62 \%$ & $78 \%$ & $89 \%$ \\
\hline Sample size & 8504 & 9522 & 21041 \\
\hline
\end{tabular}

ELSA, English Longitudinal Study on Ageing; HRS, Health and Retirement Study; TILDA, The Irish Longitudinal Study on Ageing.

meeting the CES-D cut-off score or self-reporting having ever received a doctor diagnosis of depression. Depression was categorised as:

- Diagnosed and asymptomatic: respondents who selfreported doctor diagnosed and did not meet CES-D cut-off score.

- Diagnosed and symptomatic: respondents who selfreported doctor-diagnosed depression and met CES-D cut-off score for depression symptoms.

- Undiagnosed depression: respondents who did not selfreport doctor-diagnosed depression and met CES-D cut-off score.

\section{Covariates}

Known factors across individual and health system levels associated with depression diagnosis and which may differ between people with and without diabetes were selected from the literature. These were sociodemographic (gender, age, ethnicity, education, marital status), physical health (presence of cardiovascular disease, number of additional chronic conditions, disability) ${ }^{10}{ }^{11}$ and access to healthcare. ${ }^{12}{ }^{24}$ Ethnicity was categorised as white or non-white. As ethnicity was unavailable in TILDA, all participants were assigned 'white'. To measure education, we applied the same procedures as other authors. ${ }^{25}$ In TILDA and ELSA, education was measured according to the International Standard Classification of Educational Degrees 97 and regrouped into 'low education' (preprimary, primary or lower secondary education), 'medium education' (secondary or postsecondary education) and 'high education' (first and second stages of tertiary education). Corresponding levels in HRS were defined as 'low education' (less than high school), 'medium education' (high school education) and 'high education' (some college or a college degree). Marital status was categorised as married, separated or divorced, widowed and never married. The presence of disability was defined as having self-reported limitations in one or more of the six basic activities of daily living or of the seven instrumental activities of daily living. ${ }^{26}$ Presence of cardiovascular disease was based on the presence of heart problems comprising angina, heart attack, congestive heart failure, a heart murmur, an abnormal heart rhythm, stroke, or any other heart trouble (TILDA and ELSA), and heart attack, coronary heart disease, angina, congestive heart failure, stroke or other heart problems (HRS). A continuous variable, other chronic conditions, was derived using selfreport doctor-diagnosed arthritis, cancer, dementia or other memory problems and lung disease. Regarding 
Table 2 Characteristics and depression status of TILDA, ELSA and HRS participants by diabetes status

\begin{tabular}{|c|c|c|c|c|c|c|}
\hline & Ireland & & England & & USA & \\
\hline & $\begin{array}{l}\mathrm{DM} \\
\mathrm{n}=629\end{array}$ & $\begin{array}{l}\text { No } D M \\
\mathrm{n}=7491\end{array}$ & $\begin{array}{l}\mathrm{DM} \\
\mathrm{n}=942\end{array}$ & $\begin{array}{l}\text { No } D M \\
\mathrm{n}=7691\end{array}$ & $\begin{array}{l}\text { DM } \\
n=4011\end{array}$ & $\begin{array}{l}\text { No DM } \\
n=14597\end{array}$ \\
\hline Female gender, $\mathrm{n}(\%)$ & $264(42)$ & $4131(53)$ & $441(46)$ & $4333(54)$ & $2186(51)$ & $8606(56)$ \\
\hline Age (mean, SD) & $67(8.7)$ & $63(9.1)$ & $69(8.9)$ & $67(9.1)$ & $66(10.1)$ & $64(11.0)$ \\
\hline Non-white ethnicity, n (\%) & Unavailable & Unavailable & $49(7)$ & $192(3)$ & $1378(23)$ & $3633(15)$ \\
\hline \multicolumn{7}{|l|}{ Education status, n (\%) } \\
\hline Low & $400(72)$ & $3973(63)$ & $375(43)$ & $2229(32)$ & $1284(26)$ & $3090(16)$ \\
\hline Medium & $162(22)$ & $2438(28)$ & $239(25)$ & $2113(28)$ & $1153(29)$ & $4222(28)$ \\
\hline High & $67(6)$ & $1080(9)$ & $256(24)$ & $2768(33)$ & $1574(45)$ & $7285(56)$ \\
\hline Other & & & $72(7)$ & $581(8)$ & & \\
\hline \multicolumn{7}{|l|}{ Marital status, n (\%) } \\
\hline Married & $419(65)$ & $5189(68)$ & $584(63)$ & $5306(70)$ & $2480(63)$ & $9394(67)$ \\
\hline Separated & $38(6)$ & $509(7)$ & $94(10)$ & $794(10)$ & $571(15)$ & $2134(14)$ \\
\hline Widowed & $115(20)$ & $1063(15)$ & $217(22)$ & $1175(15)$ & $760(16)$ & $2294(12)$ \\
\hline Never married & $57(9)$ & $730(10)$ & $47(5)$ & $416(5)$ & $200(6)$ & $775(7)$ \\
\hline Disability, n (\%) & $128(22)$ & $751(11)$ & $336(38)$ & $1534(20)$ & $1304(30)$ & $2724(16)$ \\
\hline CVD, n (\%) & $207(33)$ & $1408(19)$ & $309(33)$ & $1600(20)$ & $1540(37)$ & $3312(20)$ \\
\hline Other chronic conditions (mean, SD) & $0.5(0.6)$ & $0.4(0.6)$ & $0.7(0.7)$ & $0.5(0.7)$ & $0.9(0.8)$ & $0.7(0.7)$ \\
\hline \multicolumn{7}{|c|}{ Health insurance, $n(\%)$} \\
\hline Any private & $299(43)$ & $4384(54)$ & $79(8)$ & $1091(14)$ & $1987(56)$ & $8713(67)$ \\
\hline Public & $287(50)$ & $2311(35)$ & $863(92)$ & $6660(86)$ & N/A & N/A \\
\hline Medicare & N/A & $\mathrm{N} / \mathrm{A}$ & $\mathrm{N} / \mathrm{A}$ & N/A & $1485(32)$ & $3811(21)$ \\
\hline Medicaid & N/A & N/A & N/A & $\mathrm{N} / \mathrm{A}$ & $155(3)$ & $386(2)$ \\
\hline None & $43(7)$ & $796(11)$ & $\mathrm{N} / \mathrm{A}$ & N/A & 384 (10) & 1687 (10) \\
\hline
\end{tabular}

CVD, cardiovascular disease; DM, diabetes mellitus; ELSA, English Longitudinal Study on Ageing; HRS, Health and Retirement Study; N/A, not applicable; TILDA, The Irish Longitudinal Study on Ageing.

health insurance, TILDA and ELSA respondents were categorised as having: (1) dual coverage-government and private, (2) private insurance only, (3) public insurance only, and (4) no health insurance. HRS respondents were categorised as having: (1) dual coverage-public and private, (2) private insurance only, (3) public insurance-Medicare, (4) public insurance-Medicaid, and (5) no health insurance.

\section{Analysis}

Prevalence of depression by diabetes status and depression diagnosis

We reported unadjusted and age-standardised depression prevalence estimates by diabetes status and depression diagnosis for each country as a percentage with corresponding 95\% CIs and further stratified estimates by sex. Age-standardised estimates were calculated separately for each survey using marginal standardisation to make inferences to the populations drawn from individual countries. ${ }^{27}$ We applied regression-based standardisation, an equivalent to direct standardisation. ${ }^{28}$ To do this, we ran age-adjusted logistic regression, followed by Stata's postestimation 'margins' command.

Association between diabetes and undiagnosed depression among people with depression

We performed crude and adjusted logistic regression among respondents who self-reported any depression. We combined the asymptomatic and diagnosed depression and symptomatic and diagnosed depression categories into one 'diagnosed' depression reference category. Covariates were added to the model in blocks: sociodemographic variables first (age, sex, ethnicity, education status, marital status, then physical health status (cardiovascular disease, number of additional chronic conditions, disability), then access to healthcare (health insurance type)).

Analyses were conducted in Stata V.15 using the 'svy' function. Data from individual surveys were analysed separately with corresponding survey sampling weights applied to adjust for differential non-response and to reduce the potential for participation or selection bias. ${ }^{18-20}$ A complete case analysis was carried out. 


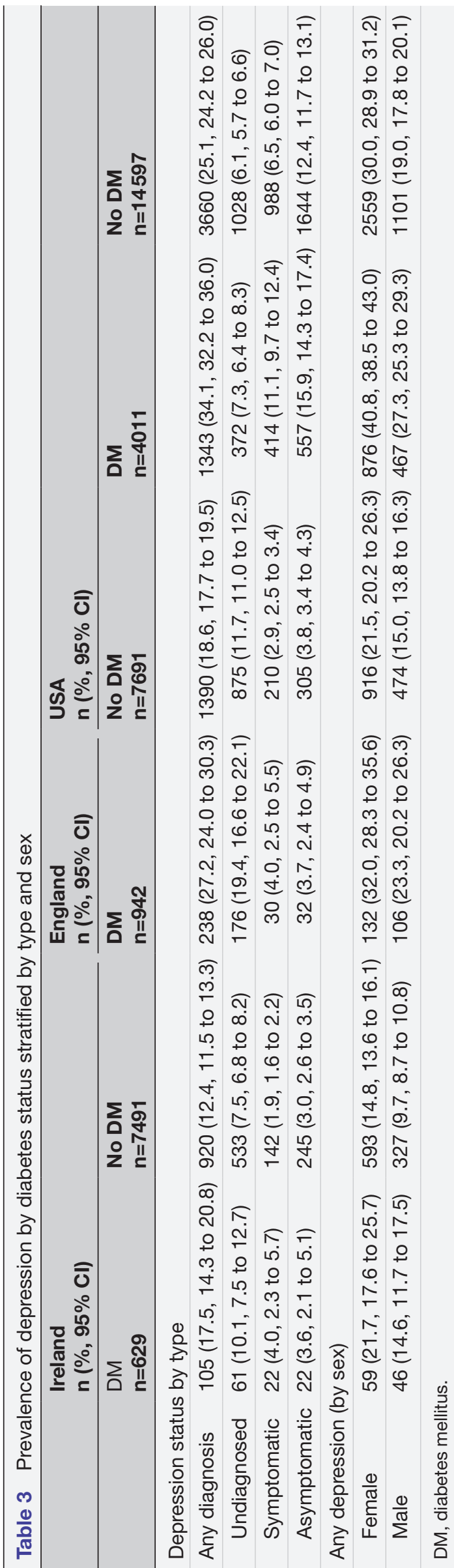

RESULTS

For the purpose of reporting the results, we refer to data relating to TILDA as 'Ireland', to ELSA as 'England' and to HRS as 'USA'.

\section{Sample characteristics}

The analytical sample was 8120 (Ireland), 8633 (England) and 18608 (USA), after removing individuals with missing data (Ireland $<1 \% \quad(\mathrm{n}=27)$, England $<1 \% \quad(\mathrm{n}=38)$, USA $3 \%(\mathrm{n}=620))$. Sample characteristics of the population by country are provided in online supplemental file 2. Respondents from England were on average older than respondents from the USA and Ireland and a higher proportion of US respondents than those from Ireland and England were female (online supplemental file 2). Prevalence of diabetes also varied across countries; Ireland: $8.0 \%$ (95\% CI $7.4 \%$ to $8.6 \%$ ), England: $11.0 \%$ (95\% CI $10.3 \%$ to $11.7 \%$ ), USA: $18.8 \%$ (95\% CI $18.1 \%$ to $19.5 \%$ ) and depression; Ireland: $12.8 \%$ (95\% CI $11.9 \%$ to $13.8 \%$ ), England: $19.5 \%$ (95\% CI $18.6 \%$ to $20.4 \%$ ), USA: $26.7 \%$ (95\% CI $25.9 \%$ to $27.6 \%$ ) (online supplemental file 2). Table 2 reports sample characteristics by diabetes status and country.

\section{Prevalence of depression by diabetes status and diagnosis}

Age-adjusted estimates are reported in table 2. Depression prevalence varied across countries but within countries, depression prevalence was higher in people with diabetes compared with those without; Ireland: $17.5 \%$ (95\% CI $14.3 \%$ to $20.8 \%$ ) vs $12.4 \%$ (95\% CI $11.5 \%$ to $13.3 \%$ ), England: $27.2 \%$ (95\% CI $24 \% .0$ to $30.3 \%$ ) vs $18.5 \%$ (95\% CI $17.6 \%$ to $19.5 \%$ ), USA: $34.1 \%$ (95\% CI $32.2 \%$ to $36.0 \%$ ) vs $25.1 \%$ (95\% CI $24.2 \%$ to $26.0 \%$ ) (table 3 ). We observed similar patterns when prevalence estimates were stratified by sex (table 3). Unadjusted depression prevalence by diabetes status and depression diagnosis is reported in online supplemental file 3 .

Prevalence of undiagnosed depression was also higher in people with diabetes; Ireland: $10.1 \%$ (95\% CI $7.5 \%$ to $12.7 \%$ ) vs $7.5 \%$ (95\% CI $6.8 \%$ to $8.2 \%$ ), England: $19.4 \%$ (95\% CI $16.6 \%$ to $22.1 \%$ ) vs $11.7 \%$ (95\% CI $11.0 \%$ to $12.5 \%$ ), USA: $7.3 \%$ (95\% CI $6.4 \%$ to $8.3 \%$ ) vs $6.1 \%(95 \%$ CI $5.7 \%$ to $6.6 \%$ ) (table 3). Age-adjusted prevalence of depression by diagnosis and diabetes status stratified by sex is reported in figures 1 and 2 . When stratified by sex, prevalence of undiagnosed depression was similar (Ireland, USA) or higher (England) in males and females with than without diabetes (figures 1 and 2). Unadjusted estimates are reported in online supplemental file 3.

\section{Association between diabetes and undiagnosed depression among people with depression}

Characteristics of people with depression by diabetes status are reported in online supplemental file 4 .

Results of the logistic regression analysis are reported in table 4 . In model 1, the unadjusted odds of undiagnosed depression were similar in people with and without diabetes in Ireland and the USA. In England, people with 


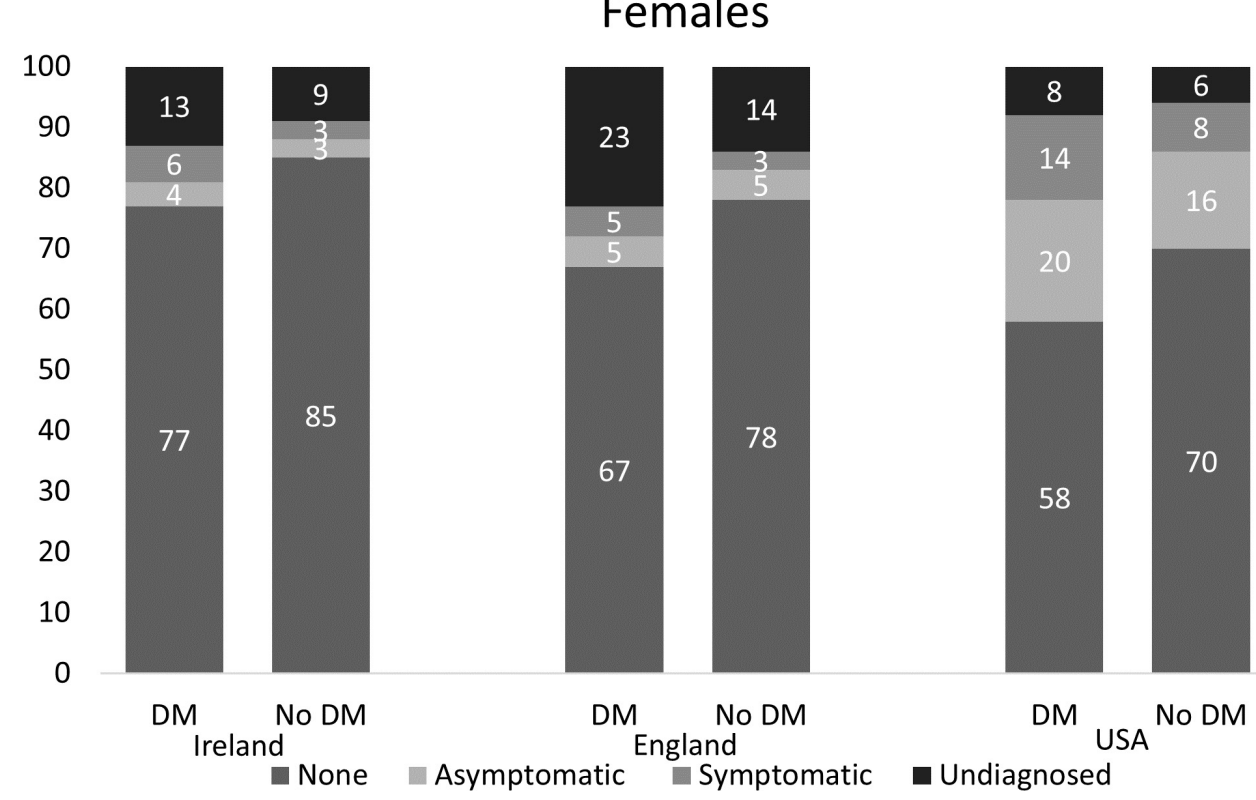

Figure 1 Age-adjusted prevalence of depression diagnoses in females with and without diabetes across countries. DM, diabetes mellitus.

diabetes had increased odds of undiagnosed depression. Adjustment for sociodemographic factors attenuated the strength of the association in each country. Addition of individual health-related factors to the model further attenuated the strength of the association in Ireland, had no effect on the strength of the association in England and increased the strength of the association in the USA. In the final model, adjustment for health insurance type further attenuated the association between diabetes and undiagnosed depression in Ireland, increased the strength of the association in England and resulted in no change in the USA. In the final model, diabetes was associated with increased odds of undiagnosed depression in England and reduced odds of undiagnosed depression in Ireland and the USA, though the $95 \%$ CI overlapped with the null in Ireland.

\section{DISCUSSION}

\section{Main findings}

Using large representative population-based samples of adults aged $\geq 50$ years in Ireland, England and the USA, depression prevalence was consistently higher among people with diabetes and varied across countries. Diabetes

\section{Males}

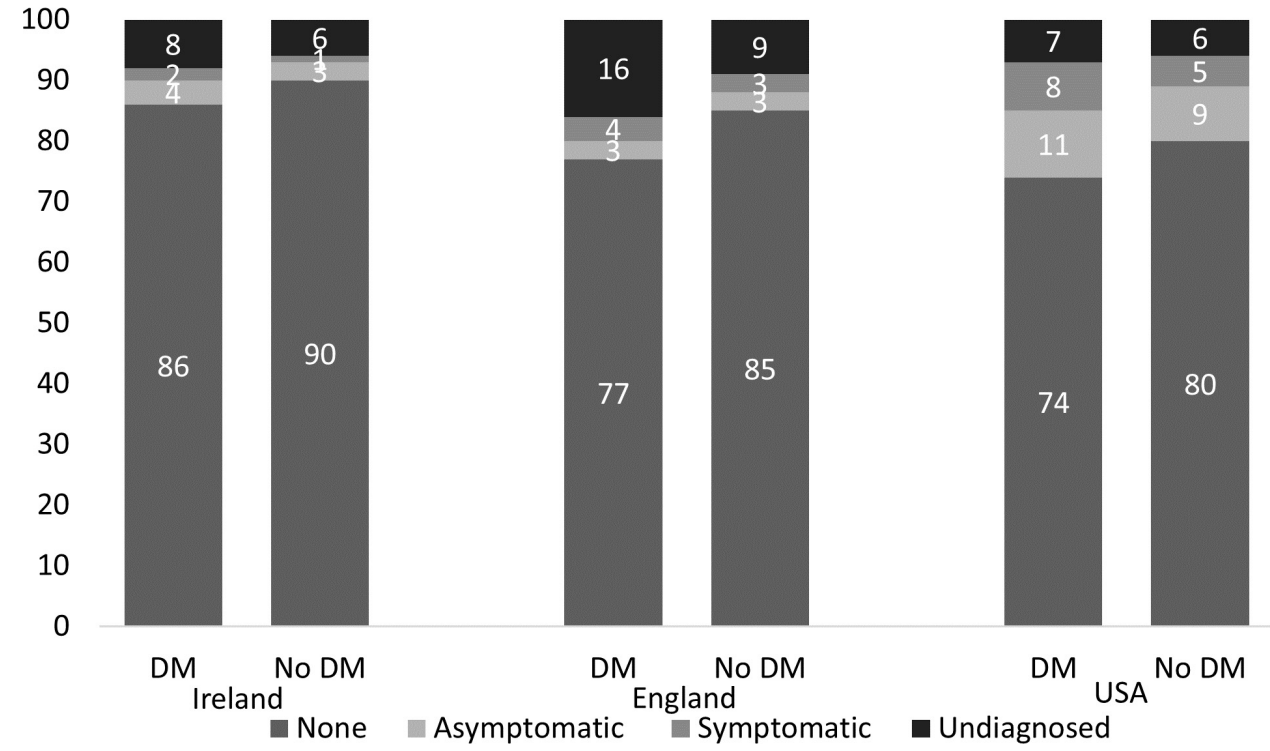

Figure 2 Age-adjusted prevalence of depression diagnoses in males with and without diabetes across countries. DM, diabetes mellitus. 
Table 4 Odds of undiagnosed (vs diagnosed) depression in people with versus without diabetes stratified by country

\begin{tabular}{|c|c|c|c|}
\hline & $\begin{array}{l}\text { Ireland }(n=1025) \\
\text { OR }(95 \% \mathrm{Cl}), P \text { value }\end{array}$ & $\begin{array}{l}\text { England }(n=1628) \\
\text { OR }(95 \% \mathrm{Cl}), \mathrm{P} \text { value }\end{array}$ & $\begin{array}{l}\text { USA }(n=5003) \\
\text { OR }(95 \% \text { CI), P value }\end{array}$ \\
\hline Model 1 & 0.99 (0.65 to 1.51$), 0.913$ & 1.71 (1.23 to 2.37 ), 0.001 & 0.90 (0.75 to 1.09 ), 0.285 \\
\hline Model 3 & 0.85 (0.53 to 1.35$), 0.479$ & 1.49 (1.05 to 2.13 ), 0.027 & 0.78 (0.64 to 0.94$), 0.012$ \\
\hline Model 4 & 0.84 (0.52 to 1.34$), 0.462$ & 1.51 (1.06 to 2.16$), 0.023$ & 0.79 (0.64 to 0.96$), 0.016$ \\
\hline
\end{tabular}

was associated with increased odds of undiagnosed depression in England and reduced odds of undiagnosed depression in Ireland and the USA.

\section{Comparison with existing literature}

Prevalence of depression by diabetes status and diagnosis Consistent with the literature, depression ${ }^{82}$ and depression diagnosis ${ }^{911}$ prevalence varied across countries. Most depression was undiagnosed in Ireland and England and diagnosed in the USA. Differences may be partly due to differences in sociodemographic and health factors influencing access to depression diagnosis. For instance, in our study, educational attainment and separation and divorce rates were higher in the USA versus other samples. ${ }^{11}$ In line with previous research, ${ }^{29}$ disability was more prevalent in our study among respondents in England and may influence undiagnosed depression via increased risk of developing depressive symptoms. ${ }^{30}$

As expected, we reported higher depression prevalence in those with diabetes. ${ }^{4}$ The difference in prevalence reported in our study (ie, approximately 1.4-1.5 times as prevalent) was smaller than is frequently reported, that is, approximately three times and twice as prevalent ${ }^{4}$ and was stable across countries. This may be partly due to our measurement of depression which included persons with current depression and with a lifetime history of depression. To our knowledge, ours is the first study to estimate and compare depression diagnosis prevalence in people with and without diabetes. The difference in prevalence of depression diagnosis varied; undiagnosed depression ranged from 1.2 times as prevalent (USA) to 1.6 times as prevalent (England) in people with versus without diabetes.

\section{Association between diabetes and undiagnosed depression among} people with depression

In Ireland and England, the proportion of people with undiagnosed depression was broadly similar to recent estimates in general populations in high-income countries ${ }^{11}$ and lower than estimates reported in type 2 diabetes populations from predominantly middle and low-income countries. ${ }^{9}$ In the USA, the proportion of people with diabetes who were undiagnosed was lower than earlier estimates $(45 \%$ and $49 \%) .{ }^{1031}$ This may be due to the larger age range of participants in these studies, that is, from 18 years and older, ${ }^{10} 31$ or new recommendations to screen for depression among adults in the USA in 2009. ${ }^{32}$

Our results suggest country-level variation in the association between diabetes and undiagnosed depression. In Ireland, diabetes was associated with reduced odds of undiagnosed depression; however, 95\% CIs included the null after adjustment for covariates. This may reflect a general gap in access to depression diagnosis among adults experiencing depression in Ireland. ${ }^{11}$ In England, higher proportions of people with diabetes compared with without had not received a depression diagnosis, even after adjustment for covariates. This was surprising, given the overall quality of diabetes care in England compared with other countries. ${ }^{16} 3334$ Possible population and healthcare professional factors should be examined to better understand the increased odds of undiagnosed depression among people with diabetes in England. Results from the USA were consistent with the limited available evidence that diabetes is associated with increased access to depression diagnosis. ${ }^{11} 14$

\section{Strengths and limitations}

The main strength of our study is the use of comparable nationally representative data. Heterogeneity in depression measurement is a typical problem in the depression and diabetes literature, ${ }^{4}$ and we used a comparable depression measure. ${ }^{23}{ }^{24}$ Our findings are generalisable to adults aged 50 years and older in Ireland, England and the USA.

There are also some limitations to the study. Primarily, a number of differences across data sets limited the scope of the analysis. Estimates would have been strengthened by capturing depression treatment (ie, medication use and/or psychological therapies), and by accounting for frequency of health service utilisation. ${ }^{25}$ However, these data were not collected in each survey. Although race is not asked in TILDA, census figures for Ireland from the year 2010 classify $98 \%$ of the population aged 50 years and older as white and as such, we did not anticipate race to influence estimates for Ireland. Second, the ability of the eight-item CES-D to screen and diagnose depression in persons with diabetes has not been assessed. However, 
given the CES-D can be used as a screening tool in the diabetes population, ${ }^{35}$ we deemed the CES-D an appropriate indicator of depression in our study. Third, the use of self-report doctor diagnoses may introduce misclassification bias, potentially leading to underestimation of diagnosed depression and overestimation of undiagnosed depression in our study. However, self-report is considered a suitable measure for estimating the prevalence of diabetes ${ }^{36}$ and depression when compared with medical records. ${ }^{37}$ Finally, our classification of diabetes only includes a small proportion of people with type 1 diabetes. For instance, type 2 diabetes accounts for approximately $1.7 \%(\mathrm{n}=11)$ of all diabetes cases in the TILDA data set. ${ }^{38}{ }^{39}$ Therefore, our results may be more reflective of the epidemiology of undiagnosed depression in people with type 2 diabetes.

\section{Implications}

Our findings have three important implications for research, policy and practice. First, the findings underscore the magnitude of undiagnosed comorbid depression and diabetes across three high-income countries with different healthcare systems. Further investigation is needed to understand high rates of undiagnosed depression in order to support implementation of recommended psychosocial care guidelines for people with diabetes, for example, mental health screening and ensuring access to appropriate mental health expertise for people with diabetes. ${ }^{40}$ Second, since diabetes distress is specific to diabetes and not currently measured in the data sets used ${ }^{18-20}$ and may also frequently go undiagnosed in people with diabetes, ${ }^{42}$ our findings may underestimate the gap in access to diagnosis for psychological comorbidity in adults aged $\geq 50$ years with versus without diabetes. Finally, longitudinal studies can play a pivotal role in understanding the psychological impact of diabetes, and monitoring strategies aimed at improving psychological aspects of diabetes care.

\section{CONCLUSION}

Among adults aged 50 years and older, in three highincome countries, undiagnosed depression was prevalent and consistently more so in people with diabetes compared with people without diabetes. Among those with depression, the influence of diabetes on the likelihood of undiagnosed depression varied by country. Taken together, the findings underscore the urgent need for targeted efforts to improve detection of depression among community-dwelling adults aged $\geq 50$ years living in high-income countries, particularly those with diabetes.

\section{Twitter Patricia M Kearney @trishcork}

Contributors NM, PMK, KON, SMM and ET formulated the overarching study aims and methodology. Data management was controlled by NM, who selected the appropriate variables, and cleaned and maintained the research data. KON and PMK provided statistical support. NM conducted the analysis and wrote the initial draft of the paper. PMK, KON, SMM and ET contributed to successive drafts, reviewing and editing. All authors read and approved the final manuscript.
Funding This study is funded by the Health Research Board, Ireland (SPHeRE/2013/1).

Disclaimer The funders had no role in study design, data collection and analysis, decision to publish or preparation of the manuscript.

Competing interests None declared.

Patient consent for publication Not required.

Ethics approval Ethical approval was obtained from the Social Research Ethics Committee (SREC), University College Cork (reference number 2018-160). TILDA was approved by the Trinity College Dublin Research Ethics Committee, ${ }^{18}$ ELSA by the South Central Berkshire Research Ethics Committee ${ }^{19}$ and HRS by the University of Michigan Health Science/Behavioral Sciences Institutional Review Board. ${ }^{20}$

Provenance and peer review Not commissioned; externally peer reviewed.

Data availability statement The datasets generated and/or analyzed during the current study are publicly available and are accessible at TILDA, ELSA and HRS on reasonable request. Data used in this study can be accessed through registration at https://www.ucd.ie/issda/data/tilda/ (TILDA), https://www.ukdataservice.ac.uk/ (ELSA) and https://hrs.isr.umich.edu/about (HRS).

Supplemental material This content has been supplied by the author(s). It has not been vetted by BMJ Publishing Group Limited (BMJ) and may not have been peer-reviewed. Any opinions or recommendations discussed are solely those of the author(s) and are not endorsed by BMJ. BMJ disclaims all liability and responsibility arising from any reliance placed on the content. Where the content includes any translated material, BMJ does not warrant the accuracy and reliability of the translations (including but not limited to local regulations, clinical guidelines, terminology, drug names and drug dosages), and is not responsible for any error and/or omissions arising from translation and adaptation or otherwise.

Open access This is an open access article distributed in accordance with the Creative Commons Attribution Non Commercial (CC BY-NC 4.0) license, which permits others to distribute, remix, adapt, build upon this work non-commercially, and license their derivative works on different terms, provided the original work is properly cited, appropriate credit is given, any changes made indicated, and the use is non-commercial. See: http://creativecommons.org/licenses/by-nc/4.0/.

\section{ORCID iDs}

Niamh McGrath http://orcid.org/0000-0002-7716-7277

Kate 0 Neill http://orcid.org/0000-0003-4843-4265

Patricia M Kearney http://orcid.org/0000-0001-9599-3540

\section{REFERENCES}

1 Cho NH, Shaw JE, Karuranga S, et al. IDF diabetes atlas: global estimates of diabetes prevalence for 2017 and projections for 2045. Diabetes Res Clin Pract 2018;138:271-81.

2 NCD Risk Factor Collaboration (NCD-RisC). Worldwide trends in diabetes since 1980: a pooled analysis of 751 population-based studies with 4.4 million participants. Lancet 2016;9;387:1513-30.

3 Bommer C, Sagalova V, Heesemann E, et al. Global economic burden of diabetes in adults: projections from 2015 to 2030. Diabetes Care 2018;41:963-70.

4 Roy T, Lloyd CE. Epidemiology of depression and diabetes: a systematic review. J Affect Disord 2012;1;142:P8-21.

5 Nouwen A, Adriaanse MC, Dam K, et al. Longitudinal associations between depression and diabetes complications: a systematic review and meta-analysis. Diabet. Med. 2019;36:1562-72.

6 van Dooren FEP, Nefs G, Schram MT, et al. Depression and risk of mortality in people with diabetes mellitus: a systematic review and meta-analysis. PLoS One 2013;8:e57058.

7 Molosankwe I, Patel A, Gagliardino JJ. Economic aspects of the association between diabetes and depression: a systematic review. $J$ Affect Disord 2012;1;142:P42-55.

8 Khaledi M, Haghighatdoost F, Feizi A, et al. The prevalence of comorbid depression in patients with type 2 diabetes: an updated systematic review and meta-analysis on huge number of observational studies. Acta Diabetol 2019;56:631-50.

9 Lloyd CE, Nouwen A, Sartorius N, et al. Prevalence and correlates of depressive disorders in people with type 2 diabetes: results from the International prevalence and treatment of diabetes and depression (INTERPRET-DD) study, a collaborative study carried out in 14 countries. Diabet. Med. 2018;35:760-9.

10 Li C, Ford ES, Zhao G, et al. Prevalence and correlates of undiagnosed depression among U.S. adults with diabetes: the 
behavioral risk factor surveillance system, 2006. Diabetes Res Clin Pract 2009;83:268-79.

11 Araya R, Zitko P, Markkula N, et al. Determinants of access to health care for depression in 49 countries: a multilevel analysis. J Affect Disord 2018;234:80-8.

12 Araya R. Zitko P, Markkula N. The Impact of Universal Health Care Programmes on Improving 'Realized Access' to Care for Depression in Chile. Adm Policy Ment Heal Ment Heal Serv Res 2018; 45(5):7909.

13 Tamblyn R, Bates DW, Buckeridge DL, et al. Multinational comparison of new antidepressant use in older adults: a cohort study. BMJ Open 2019;9:27663.

14 Borowsky SJ, Rubenstein LV, Meredith LS, et al. Who is at risk of nondetection of mental health problems in primary care? $J$ Gen Intern Med 2000;15:381-8.

15 Cebolla Garrofé B, Björnberg A, Phang AY. Euro diabetes index 2014. Marseillan, France: Health Consumer Powerhouse LTD, 2014.

16 Graham EA, Thomson KH, Bambra CL. The association between diabetes and depressive symptoms varies by quality of diabetes care across Europe. Eur J Public Health 2018;28:872-8.

17 Holt RIG, Nicolucci A, Kovacs Burns K, et al. Diabetes attitudes, wishes and needs second study (DAWN2 ${ }^{\mathrm{TM}}$ ): cross-national comparisons on barriers and resources for optimal care-healthcare professional perspective. Diabet. Med. 2013;30:789-98.10.1111/ dme.12242

18 Kenny A, Anne R, Cronin H. The design of the Irish longitudinal study on ageing. Dublin: Trinity College Dublin, 2010.

19 Steptoe A, Breeze E, Banks J, et al. Cohort profile: the English longitudinal study of ageing. Int J Epidemiol 2013;42:1640-8.

20 Sonnega A, Faul JD, Ofstedal MB, et al. Cohort profile: the health and retirement study (HRS). Int J Epidemiol 2014;43:576-85.

21 Karim J, Weisz R, Bibi Z, et al. Validation of the Eight-Item center for epidemiologic studies depression scale (CES-D) among older adults. Curr Psychol 2015;34:681-92.

22 O'Halloran AM, Kenny RA, King-Kallimanis BL. The latent factors of depression from the short forms of the CES-D are consistent, reliable and valid in community-living older adults. Eur Geriatr Med 2014;5:97-102.

23 Steffick D, Wallace R, Herzog A. Documentation of affective functioning measures in the health and retirement study. Ann Arbour, MI: University of Michigan, 2000.

24 Williams SZ, Chung GS, Muennig PA. Undiagnosed depression: a community diagnosis. SSM - Population Health 2017;3:633-8.

25 Rippon I, Zaninotto P, Steptoe A. Greater perceived age discrimination in England than the United States: results from Hrs and ELSA. J Gerontol B Psychol Sci Soc Sci 2015;70:925-33.

26 LaPlante MP. The classic measure of disability in activities of daily living is biased by age but an expanded IADL/ADL measure is not. $J$ Gerontol B Psychol Sci Soc Sci 2010;65:720-32.

27 Muller CJ, MacLehose RF. Estimating predicted probabilities from logistic regression: different methods correspond to different target populations. Int J Epidemiol 2014;43:962-70.
28 Roalfe AK, Holder RL, Wilson S. Standardisation of rates using logistic regression: a comparison with the direct method. $B M C$ Health Serv Res 2008;8:275.

29 Zivin K, Llewellyn DJ, Lang IA, et al. Depression among older adults in the United States and England. Am J Geriatr Psychiatry 2010;18:1036-44.

$30 \mathrm{He} \mathrm{M}, \mathrm{Ma}$ J, Ren Z, et al. Association between activities of daily living disability and depression symptoms of middle-aged and older Chinese adults and their spouses: a community based study. $J$ Affect Disord 2019;242:135-42.

31 Katon WJ, Simon G, Russo J, et al. Quality of depression care in a population-based sample of patients with diabetes and major depression. Med Care 2004;42:1222-9.

32 Calonge N, Petitti DB, DeWitt TG. Screening for depression in adults: U.S. preventive services Task force recommendation statement. Ann Intern Med 2009;151:784-92.

33 Stone MA, Charpentier G, Doggen K. Quality of care of people with type 2 diabetes in eight European countries: findings from the Guideline adherence to enhance care (guidance) study. Diabetes Care 2013;36:2628-38.

34 Si D, Bailie R, Wang Z, et al. Comparison of diabetes management in five countries for general and Indigenous populations: an Internetbased review. BMC Health Serv Res 2010;10:169.

35 de Joode JW, van Dijk SEM, Walburg FS, et al. Diagnostic accuracy of depression questionnaires in adult patients with diabetes: a systematic review and meta-analysis. PLoS One 2019;14:e0218512.

36 Okura Y, Urban LH, Mahoney DW, et al. Agreement between selfreport questionnaires and medical record data was substantial for diabetes, hypertension, myocardial infarction and stroke but not for heart failure. J Clin Epidemiol 2004;57:1096-103.

37 Townsend L, Walkup JT, Crystal S. A systematic review of validated methods for identifying depression using administrative data. Pharmacoepidemiol Drug Saf 2012;21:163-73.

38 Leahy S, O' Halloran AM, O' Leary N, et al. Prevalence and correlates of diagnosed and undiagnosed type 2 diabetes mellitus and prediabetes in older adults: findings from the Irish longitudinal study on ageing (TILDA). Diabetes Res Clin Pract 2015;110:241-9.

39 Tracey ML, McHugh SM, Buckley CM, et al. The prevalence of type 2 diabetes and related complications in a nationally representative sample of adults aged 50 and over in the Republic of Ireland. Diabet Med 2016;33:441-5. doi:10.1111/dme.12845

40 Aschner P. New IDF clinical practice recommendations for managing type 2 diabetes in primary care. Diabetes Res Clin Pract 2017;132:169-70.

41 Young-Hyman D, de Groot M, Hill-Briggs F, et al. Psychosocial care for people with diabetes: a position statement of the American diabetes association. Diabetes Care 2016;39:2126-40.

42 Pouwer F, Beekman ATF, Lubach C, et al. Nurses' recognition and registration of depression, anxiety and diabetes-specific emotional problems in outpatients with diabetes mellitus. Patient Educ Couns 2006;60:235-40. 